\title{
A violência contra o idoso: dimensão ética e política de uma problemática em ascensão ${ }^{1}$
}

Violence against the elderly: ethical and political dimensions of an ascendant problematic

\author{
La violencia contra el anciano: una dimensión ética y política de una problemática en \\ ascensión
}

Márcia Virgínia Di Lorenzo Florêncio', Maria de Oliveira Ferreira Filha", Lenilde Duarte de Sál"'

\begin{abstract}
RESUMO
A violência contra os idosos é um fenômeno evidente dentro do atual processo de envelhecimento populacional mundial. Este artigo tem como objetivo apresentar uma reflexão sobre o tema da violência contra os idosos, apoiada em artigos científicos publicados. Trata-se de uma atualização, que além de abordar temas principais do assunto, pretende enfatizar como o mesmo é tratado pela atual política de saúde do idoso no Brasil, e também dar um enfoque ético. Percebe-se que a questão da violência contra os idosos é pouco considerada pela sociedade em geral e pelos profissionais de saúde. No Brasil existe uma política de promoção da saúde dos idosos e de prevenção à violência que ainda não está implementada em sua totalidade, e nem de acordo com as singularidades de cada região. Os enfermeiros, mais especificamente, precisam tratar com empatia e resolutividade os casos de violência contra idosos por eles identificados.
\end{abstract}

Palavras chave: Violência; Idosos; Serviços de Saúde para Idosos; Política de Saúde; Ética.

\footnotetext{
ABSTRACT

Elder abuse is an evident phenomenon into the current worldwide ageing population. This paper intents to show a reflection about elder abuse, based on scientific reviews. This is an actualization paper that intents to approach the main themes about the matter; also aims to emphasize how this subject is treated by the current elder health policy in Brazil, by an ethical focus. It was noticed that elders abuse is a low worked matter by the society and health professionals. Brazil has a policy of promotion and prevention on elder abuse, that do not have been fully implemented yet, neither by the singularity of each area. Nurses, specifically, have to treat their abused patients with empathy and resolubility.
}

Key words: Violence; Elder; Health Services for the Aged; Health Policy; Ethics.

\section{RESUMEN}

La violencia contra los ancianos es un fenómeno evidente dentro del actual proceso de envejecimiento poblacional mundial. Este artículo tiene como objetivo presentar una reflexión sobre el tema de la violencia contra los ancianos, apoyado en artículos científicos publicados. Se trata de una actualización, que además de abordar temas principales del asunto, pretende enfatizar cómo el mismo es tratado por la atual política de salud del anciano en Brasil, y también dar un enfoque ético. Se percibió que la cuestión de la violencia contra ancianos es poco considerada por la sociedad en general y por los profesionales de salud. En Brasil existe una política de promoción de la salud del anciano y de prevención a la violencia que aún no está implementada en su totalidad, de acuerdo con las singularidades de cada región, para que se puedan obtener mejoras efectivas. Los enfermeros más específicamente necesitan cuidar con empatía y resolutividad los casos de violencia contra ancianos por ellos identificados.

\footnotetext{
${ }^{1}$ Trabalho de conclusão da disciplina de Políticas em Saúde do Programa de Pós Graduação em Enfermagem da Universidade Federal da Paraíba

' Enfermeira, licenciada em Enfermagem pela Universidade Federal da Paraíba, Especialista em Enfermagem Médico Cirúrgica pelo Programa de Residência em Enfermagem da Universidade Federal de Pernambuco, Mestranda do Programa de Pós Graduação em Enfermagem da Universidade Federal da Paraíba. João Pessoa-PB. E-mail: marciadilorenzo@bol.com.br

"Enfermeira, Profáa. Dra $\underline{a}$ em Enfermagem. Docente do Programa de Pós Graduação em Enfermagem da Universidade Federal da Paraíba/Brasil. Expert em Saúde Mental. E-mail: marfilha@yahoo.com.br

III Enfermeira, Profáa. Dra em Enfermagem. Docente do Programa de Pós Graduação em Enfermagem da Universidade Federal da Paraíba/Brasil. Expert em Saúde Coletiva. E-mail: lenilde@ccs.ufpb.br
} 
Florêncio MVL, Ferreira Filha MO, Sá LD. A violência contra o idoso: dimensão ética e política de uma problemática em ascensão. Revista Eletrônica de Enfermagem [serial on line] 2007 Set-Dez; 9(3):847-857. Available from: URL: http://www.fen.ufg. br/revista/v9/n3/v9n3a23.htm

Palabras clave: Violencia; Ancianos; Servicios de salud para los ancianos; Política de Salud,

\section{NTRODUÇÃO}

O envelhecimento populacional é um fenômeno mundial crescente que progride em velocidades diferentes de acordo com o estágio de desenvolvimento econômico dos diversos países ${ }^{(1)}$.

Nos países desenvolvidos, o fenômeno delineia-se há mais de um século, em virtude de características inerentes a um elevado índice de desenvolvimento humano e a distribuição mais eqüitativa dos bens de consumo, que proporcionam condições de vida mais confortáveis, de bem estar social e de saúde, com conseqüente aumento da longevidade (2). Entretanto nos países em desenvolvimento, 0 processo de envelhecimento tem ocorrido de forma muito acelerada nos últimos quarenta anos, em decorrência principalmente da queda da fecundidade, da natalidade, e da mortalidade, mais do que em relação ao aumento da longevidade, resultando indiretamente, no aumento da expectativa de vida ${ }^{(1)}$.

A probabilidade de envelhecimento da população brasileira ocorrerá (3) em ritmo maior do que aquele ocorrido nos países do Primeiro Mundo. Tais países já convivem com populações menos jovens, por nunca terem experimentado níveis tão altos de fecundidade quanto o Brasil.

Constata-se também que os países economicamente desenvolvidos vieram ao longo do processo de envelhecimento, adaptando suas sociedades (do ponto de vista social, político, econômico e familiar) para lidar
Ética.

com o fenômeno do envelhecimento. Entretanto, este fato não foi observado nos países em desenvolvimento, que no momento ainda não se encontram preparados para o impacto que tal mudança pode causar aos diversos seguimentos da sociedade. Em decorrência, diversos conflitos se estabelecem, sejam de ordem familiar, econômica, política, previdenciária, social, de gênero, ou de saúde (3).

No caso do Brasil, são muitas as necessidades dos idosos que não são supridas pela atual conjuntura social e política instalada. O Brasil (1) possui dois grupos populacionais economicamente não produtivos, os idosos e as crianças (inclui-se os jovens), e a carga de dependência desses grupos em relação à parcela economicamente produtiva é medida pelo índice de dependência. Numa projeção para o ano de $2025^{(1)}$, o índice de dependência dos idosos se elevará acentuadamente, implicando em alto custo financeiro. Porém sabe-se que a distribuição de recursos destinados a essas duas parcelas não é igualitária nas necessidades de cada uma delas:

A convivência dos idosos com indivíduos mais jovens, e a dependência obrigatória podem gerar conflitos, a ponto de a relação entre ambos ficar insustentável, sem abertura para o diálogo e a argumentação franca. Isto ocorreria no âmbito familiar, institucional e no convívio social. Nestas situações é comum acontecer o fenômeno da violência contra o idoso. 
Florêncio MVL, Ferreira Filha MO, Sá LD. A violência contra o idoso: dimensão ética e política de uma problemática em ascensão. Revista Eletrônica de Enfermagem [serial on line] 2007 Set-Dez; 9(3):847-857. Available from: URL: http://www.fen.ufg. br/revista/v9/n3/v9n3a23.htm

$\mathrm{Na}$ medida em que o envelhecimento populacional acontece no mundo inteiro, o fenômeno da violência contra os idosos também cresce. Na verdade, a palavra mais adequada a ser usada é "aparece". Durante muito tempo os diversos atos de violência contra os idosos foram tidos como problemas particulares de cada família, embaçados por contextos culturais, não sendo captada sua relevância pelo olhar do profissional de saúde, e nem cabendo, portanto, qualquer intervenção por parte do Estado.

O despertar da sociedade para a questão do abuso aos idosos (2-4) “[...] do ponto de vista antropológico e cultural (...), vem junto com a elevação da consciência de direitos", inclusive dos próprios idosos. O elevado crescimento nas proporções de idosos em quase todos os países do mundo repercute em maior visibilidade social do grupo e maior relevância na expressão de suas necessidades.

A violência contra os idosos ocorre de diferentes formas, e por isso mesmo, sua identificação se torna difícil dependendo do contexto cultural em que esteja inserida. Nas palavras de Nelson Mandela, publicadas no relatório mundial sobre violência da OMS (5) "Muitos dos que convivem com a violência dia após dia assumem que ela é parte intrínseca da condição humana, mas isto não é verdade." Caso seja, defendemos sua prevenção e/ou combate.

A Organização Mundial de Saúde (5) define violência da seguinte forma: "O uso intencional da força física ou do poder, real ou em ameaça, contra si próprio, contra outra pessoa, ou contra um grupo ou uma comunidade, que resulte ou tenha grande probabilidade de resultar em lesão, morte, dano psicológico, deficiência de desenvolvimento ou privação".

A Rede Internacional para a Prevenção dos Maus Tratos contra o Idoso adotou a seguinte definição, em 1995, na Inglaterra, para a violência contra o idoso (2): "o maltrato ao idoso é um ato (único ou repetido) ou omissão que the cause dano ou aflição e que se produz em qualquer relação na qual exista expectativa de confiança". Tal ato se refere aos abusos físicos, psicológicos, sexuais, abandono, negligências, abusos financeiros, e autonegligência. Frequentemente podem acontecer ao mesmo tempo vários tipos de maus tratos.

Sob um ponto de vista mais generalista, as formas de violência contra o idoso advêm do conflito de interesses entre as gerações jovens e idosas. O fato de o idoso ser considerado, na sociedade, um sujeito improdutivo, dependente sob vários aspectos (econômico, familiar, de saúde), e obsoleto do ponto de vista cultural (aquele que não acompanha as novas formas de atitude e de visão de mundo), torna-o um ser marginalizado, excluído dos acontecimentos, e desperta nos mais jovens um desejo coletivo inconsciente de sua morte (4).

É difícil estimar em números, inclusive mundialmente, o peso da violência contra os idosos. São escassas as fontes de dados confiáveis e expressivas. Isto porque o fato é oculto pelas famílias, e também porque os profissionais de saúde ainda não focalizam seu olhar clínico para a detecção do problema (gerando registros imprecisos nos prontuários hospitalares). Ainda não há uma consciência coletiva de denúncia dos abusos, assim como não há em todas as cidades serviços 
Florêncio MVL, Ferreira Filha MO, Sá LD. A violência contra o idoso: dimensão ética e política de uma problemática em ascensão. Revista Eletrônica de Enfermagem [serial on line] 2007 Set-Dez; 9(3):847-857. Available from: URL: http://www.fen.ufg. br/revista/v9/n3/v9n3a23.htm

destinados à receptação de tais denúncias (ex: sos idoso).

Pelo exposto acima percebe-se que a violência contra o idoso é um fenômeno que ainda carece ser estudado sob vários aspectos. O debate franco com a sociedade acerca do tema, a prevenção do abuso, a identificação e encaminhamento correto dos casos, são pontos vitais para que o respeito ao idoso vitimado seja reinstalado, afim de que ele possa viver seu envelhecimento de forma tranqüila, gozando plenamente de suas capacidades físicas e mentais ainda preservadas, sem temor, opressão ou tristeza ${ }^{(6)}$. Para tanto é preciso que tal temática seja levada à discussão por diferentes seguimentos da sociedade (escolas, igrejas, família, políticos), incluindo os próprios idosos.

Conseguir identificar adequadamente quando uma pessoa idosa está sendo submetida a situações de maus tratos e/ou negligência é importante na manutenção da sua saúde e na prevenção de agravos. O papel do enfermeiro neste ponto é de grande importância, por ser ele o ente da equipe multiprofissional que tem acesso direto ao cliente, nas diferentes complexidades de assistência à saúde. O enfermeiro deve estar bem preparado para identificar casos de abusos contra idosos, bem como dar encaminhamento correto a cada situação, atentando para a satisfação das necessidades físicas, sociais e emocionas da cada vítima.

Este trabalho tem como objetivo realizar uma reflexão sobre o tema da violência contra os idosos, amparada em artigos científicos publicados. Trata-se de um artigo de atualização, que além de abordar os enfoques principais do assunto, pretende destacar como o tema é trabalhado pela atual política de saúde do idoso no Brasil.

Para tanto foi feita uma pesquisa no acervo de bibliotecas virtuais, como o SciELO, LILACS, e Google, bem como foram coletadas publicações do governo brasileiro (leis, portarias, cartilhas orientadoras). Ainda foram consultados livros, dissertação de mestrado, e publicações on line da OMS. Os dados foram coletados nos meses de junho e julho de 2006, na língua portuguesa. No total foram consultadas 20 publicações referentes à temática em estudo.

De acordo com o exercício de reflexão sobre a produção nacional da problemática em questão, foram identificados textos que tratam da violência para com os idosos enfocando principalmente os seguintes temas: políticas de saúde, legislação, características do fenômeno da violência, e ainda dados sobre morbidade e mortalidade por "causas externas" (é sob este termo que se abrigam as possíveis ocorrências de violência), formas de prevenção da violência para com os idosos, além de exploração da temática do envelhecimento e dos fatores causadores de violência para com as pessoas desta faixa etária.

Os dados encontrados foram agrupados e analisados de acordo com os temas que se pretendeu abordar no estudo: características sócio-epidemiológicas do fenômeno; o papel da família na violência contra o idoso; a política e a legislação de proteção ao idoso; questões éticas do enfrentamento da violência contra o idoso.

CARACTERÍ STI CAS

sócio-

EPI DEMI OLÓGI CAS DO FENÔMENO 
Florêncio MVL, Ferreira Filha MO, Sá LD. A violência contra o idoso: dimensão ética e política de uma problemática em ascensão. Revista Eletrônica de Enfermagem [serial on line] 2007 Set-Dez; 9(3):847-857. Available from: URL: http://www.fen.ufg. br/revista/v9/n3/v9n3a23.htm

É do seguimento de pessoas com 60 a 75 anos que surgem as principais denúncias de maus-tratos. Nesta faixa etária boa parte dos idosos é ativa física e intelectualmente, e dispõem de mais autonomia e condições de procurar por ajuda. O que não significa dizer, que acima desta idade o fenômeno da violência não ocorra. Os grupos de 80 a 90 anos, por sua fragilidade, requerem uma atenção ainda maior no atendimento de suas necessidades de saúde e na prevenção das várias formas de violência ${ }^{(7)}$.

Em um levantamento feito nas Delegacias de Proteção ao Idoso de Belo Horizonte e São Paulo (8), as queixas mais freqüentes dos idosos dizem respeito a delitos de lesão corporal, furtos, maus-tratos, injúria, extravios de documentos, mal uso dos bens dos idosos pelos próprios familiares, perturbações da ordem, ameaças, abandono material, apropriação indébita.

Um estudo realizado na cidade de Ribeirão Preto em $2002{ }^{(9)}$ verificou que a maioria dos idosos, vítimas de violência que fizeram boletim de ocorrência nas delegacias, o fez por conta de lesões corporais. As denúncias de abuso sexual e psicológico foram mínimas.

As atuais fontes de dados disponíveis sobre o tema ${ }^{(10,7)}$ permitem retratar a questão da violência contra o idoso de uma perspectiva apenas clínico-biológica, negligenciando-se a violência que ocorre dentro do lar. As atenções são mais voltadas para as necessidades físicas decorrentes de quedas, acidentes de trânsito (atropelamentos, quedas por transporte inadequado), homicídios (sem diferenças de proporção em relação à população em geral), suicídios (mais significativo neste grupo em relação à média da população). Estima-se (7) que “[...] cerca de $70 \%$ das lesões e dos traumas sofridos pelos velhos não comparecem às estatísticas". Os registros atuais disponíveis constituem (7) " $[\ldots]$ a ponta do iceberg de uma cultura relacional de dominação, de conflitos intergeracionais ou de negligências familiares ou institucionais". O grande bloco de gelo de maus tratos está submerso sob uma tênue linha d'água, que a sociedade, o Estado e as famílias aparentemente não percebem.

De todas as formas de abuso a mais freqüente é aquela de cunho financeiro. São tentativas dos familiares de se apoderarem das fontes de renda do idoso, ou de seus bens e economias, ainda em vida. Os parentes mais próximos é que são os atores (filhos, conjugues, genros e noras), apossam-se da renda, da casa, dos outros bens, e não é raro acontecer de deixarem faltar subsídios para o próprio idoso ${ }^{(7) .}$

Hoje no Brasil, cerca de $70 \%$ dos idosos vive em situação de pobreza ou miserabilidade. Mesmo aqueles que são pobres, vêem-se na obrigação de contribuir na renda familiar com o parco dinheiro de suas aposentadorias, ou até mesmo de servir de arrimo de família com tão pouca quantia (1). Após a aposentadoria (11) os idosos sentem-se inferiorizados tendem a ser considerados inúteis e improdutivos “( ...) o que acaba gerando seu isolamento do convívio social como forma de preservação". É importante citar que o abuso financeiro também é praticado pelo Estado, por lojas, bancos e empresas (como os planos de saúde).

Também existe a violência institucional (7), que “[...] se realiza como uma forma de agressão política, cometida pelo estado, em nível macrossocial e, de maneira mais específica, nas instituições públicas de 
Florêncio MVL, Ferreira Filha MO, Sá LD. A violência contra o idoso: dimensão ética e política de uma problemática em ascensão. Revista Eletrônica de Enfermagem [serial on line] 2007 Set-Dez; 9(3):847-857. Available from: URL: http://www.fen.ufg. br/revista/v9/n3/v9n3a23.htm

prestação de serviços e nas públicas e privadas de longa permanência".

\section{O PAPEl da família na VIOLÊnCIA CONTRA O IDOSO: DE SALVAGUARDA A ALGOZ}

Considerando a literatura investigada, a família é hoje a entidade mais causadora de violência aos idosos. Isso não só no aspecto financeiro, como já foi dito, mas também nas outras formas de abuso. Estudos (7) mostram que $90 \%$ dos casos de violência e de negligência contra as pessoas acima de 60 anos ocorrem nos lares.

Os conceitos de violência familiar e violência doméstica são bem próximos. A violência familiar implica na existência de laços de parentesco entre a vítima e o agressor, ocorre, portanto, ligada ao laço familiar, dentro ou fora do domicílio da vítima. Já a violência doméstica implica em proximidade do agressor para com sua vítima, não exatamente ligada a laços de parentesco, podendo, portanto, ser exercida por pessoas que compartilhem o espaço doméstico do idoso, como empregados, agregados ou visitantes ${ }^{(12)}$. Tais definições servem para ilustrar que o agressor do idoso é, na maioria das vezes, alguém próximo do mesmo, o que torna $o$ ato de violência ainda mais covarde, já que praticado por um inimigo íntimo, conhecedor de minúcias em relação à vida e as fraquezas do idoso (inclusive afetivas).

A dependência, seja ela de qualquer um ou de ambos os lados, é um fator que aumenta o risco de violência.

A dependência econômica de filhos adultos em relação à pais idosos é muito aparente no Brasil, e consiste em fator de risco, especialmente quando o idoso é a única fonte de recursos da família ${ }^{(13)}$.

A dependência do idoso em relação à sua família aumenta a proximidade, o que pode resultar em aspectos positivos ou negativos na relação. Se a dependência for causada por adoecimento, as chances de aumento de estresse, cansaço físico e emocional, e sobrecarga sobre a família (principalmente sobre o cuidador) se elevam, e complicam a relação ${ }^{(12,14)}$.

Colabora neste desequilíbrio familiar a mudança de conjuntura da atual família brasileira: menor número de filhos (menor número de pessoas para cuidar dos pais na velhice); marido e mulher trabalhando fora (quem está em casa para cuidar dos idosos e das crianças?); migração dos jovens para outras regiões em busca de trabalho, deixando os pais idosos nas terras natais; divórcios; diminuição do poder aquisitivo; lares fisicamente menores; alcoolismo; uso de drogas.

A convivência e a co-dependência de ambas as partes pode gerar conflitos que resultam em atos de violência. É quando então, no cotidiano, presenciam-se cenas de exploração e dependência econômica dos idosos pelos mais jovens, maus tratos físicos e afetivos, negligências quanto ao estado de saúde, tão frágil e peculiar nesta fase ${ }^{(2)}$.

A literatura já descreve características e fatores ligados ao perfil do agressor de idosos mais comumente identificado na nossa sociedade (7): mora com a vítima; é financeiramente dependente dela; abusa de álcool e drogas; vínculos familiares frouxos; pouca comunicação e afeto; isolamento social dos familiares da pessoa de idade avançada, o 
Florêncio MVL, Ferreira Filha MO, Sá LD. A violência contra o idoso: dimensão ética e política de uma problemática em ascensão. Revista Eletrônica de Enfermagem [serial on line] 2007 Set-Dez; 9(3):847-857. Available from: URL: http://www.fen.ufg. br/revista/v9/n3/v9n3a23.htm

idoso ter sido ou ser uma pessoa agressiva nas relações com seus familiares; história pregressa de violência na família; os cuidadores terem sido vítimas de violência doméstica ; padecerem de depressão ou de qualquer tipo de sofrimento mental ou psiquiátrico.

Dados curiosos ainda precisam ser acrescidos: a violência é praticada também por filhas mulheres; se transmite por gerações, pois é freqüente que o agressor seja um neto (a) ou bisneto (a); as mulheres são vítimas comuns e mais numerosas, o que reflete a violência de gênero adentrando na terceira idade ${ }^{(15)}$.

\section{A POLÍticA E A LEGISLAÇÃo DE PROTEÇÃO AO IDOSO}

O Estado brasileiro, ao longo dos últimos vinte anos, construiu alguns dispositivos legais de amparo à pessoa idosa, entre eles os que estão inscritos na Constituição Federal, constituindo diretrizes para a elaboração da Política Nacional de Saúde do Idoso, além do Estatuto do Idoso ${ }^{(7)}$. Todavia, diante da realidade de violência parece que apenas a existência de dispositivos não é suficiente para o enfrentamento do problema.

Conforme a Constituição Federal, o idoso é um sujeito de direitos; está impedida qualquer forma de discriminação por idade; e compete à família, à sociedade e ao Estado “[...] o dever de amparar o idoso, assegurar sua participação na comunidade, defender sua dignidade e bem-estar, e garantir seu direito à vida" (8).

A Lei Orgânica da Saúde, no 8.080/90, traz o princípio da "preservação da autonomia das pessoas na defesa de sua integridade física e moral" (16). Já o Estatuto do idoso, Lei no 10.741, no seu capítulo IV, “Do Direito à Saúde", assegura ao idoso o direito à atenção integral em saúde, através do Sistema Único de Saúde, com toda a totalidade de serviços que este sistema puder prestar, incluindo ainda atenção especial às doenças que afetem preferencialmente esta parcela da população. Especificamente para os idosos estão previstos, além de outros direitos comuns aos demais cidadãos, a criação de unidades geriátricas de referência; atendimento domiciliar com internações domiciliares, caso necessário.

O Estatuto proíbe a cobrança diferenciada de valores de planos de saúde pelos idosos com a justificativa do avanço da idade. Um aspecto de grande relevância para esta análise é o artigo 19 do Estatuto do I doso que trata da obrigatoriedade de comunicação, por parte dos profissionais de saúde, dos casos de suspeita ou confirmação de maus tratos contra o idoso, aos seguintes órgãos públicos: autoridade policial, Ministério Público, Conselho Municipal do Idoso, Conselho Estadual do Idoso, e Conselho Nacional do Idoso ${ }^{(17)}$.

O Estatuto ainda prevê as seguintes prioridades no atendimento ao idoso ${ }^{(8)}$ : serviços de atendimento às vítimas de violência (inclusive preventivo), localização de familiares de idosos abandonados em instituições, suporte jurídico-social, ampliação da participação social no atendimento ao idoso.

A Portaria 1395/GM, de 10 de dezembro de 1999, trata da Política Nacional de Saúde do Idoso, estabelecendo entre seus princípios que “[...] a família, a sociedade e o estado têm o dever de assegurar ao idoso todos os direitos de cidadania, garantindo sua participação na comunidade, defendendo sua dignidade, seu 
Florêncio MVL, Ferreira Filha MO, Sá LD. A violência contra o idoso: dimensão ética e política de uma problemática em ascensão. Revista Eletrônica de Enfermagem [serial on line] 2007 Set-Dez; 9(3):847-857. Available from: URL: http://www.fen.ufg. br/revista/v9/n3/v9n3a23.htm

bem-estar e seu direito à vida" ${ }^{(8)}$. Em relação aos maus tratos contra idosos, a Portaria afirma ${ }^{(16)}$ que os profissionais de saúde devem estar sempre atentos para a possível existência deste mal, causado por parte da família, do cuidador, ou de outros profissionais; e que os idosos devem saber reconhecer seus sinais. Ainda afirma que idosos, familiares e profissionais devem sempre denunciar casos suspeitos de violência contra o idoso.

No ano de 2000 foi lançada no Brasil a Política Nacional de Redução da Mortalidade por Acidentes e Violência, que enfatiza a promoção da saúde para o alcance da qualidade de vida, prioriza as ações preventivas intersetoriais e a ação comunitária. Suas principais diretrizes são: promoção da adoção de comportamentos e de ambientes seguros e saudáveis; monitorização da ocorrência de acidentes e violência; sistematização, ampliação e consolidação do atendimento pré-hospitalar; assistência interdisciplinar e intersetorial às vítimas de acidentes e de violência; estruturação e consolidação do atendimento voltado à recuperação e à reabilitação; capacitação de recursos humanos; apoio ao desenvolvimento de estudos e pesquisas.

Em 2002 foi lançado em Madri o II Plano de Ação para o Envelhecimento, que serviu de Base para a criação do Plano de Ação para Enfrentamento da Violência contra a Pessoa Idosa (PAEVPI), pela Subsecretaria de Direitos Humanos da Secretaria Geral da Presidência da República do Brasil. "O Plano tem por objetivo promover ações que levem ao cumprimento do Estatuto do Idoso (Lei no 10741/2003), em conformidade com o Plano de Madri, que tratam do enfrentamento da exclusão social e de todas as formas de violência contra a pessoa idosa, assim como garantir os direitos fundamentais" (18).

O PAEVPI prevê, igualmente, ações de combate e prevenção a todas as formas de violência já identificadas contra os idosos, com responsabilidades, atribuições, e estratégias divididas para o espaço cultural coletivo, público, família, e instituições asilares. Dentre as várias ações estratégicas citadas no Plano para cada um destes setores, algumas já foram implementadas, como: a criação de Delegacias Especializadas para idosos; criação de fóruns específicos; criação de sistema de denúncia; de promotorias e Defensorias Públicas, e de Conselhos Municipais e Estaduais de Direitos da Pessoa Idosa; capacitação de profissionais de saúde, de direito, de assistência social, conselheiros, idosos, sociedade, e gestores de instituições asilares, entre outras ações.

Conforme as considerações acima descritas o Brasil atualmente possui suficientes recursos legais para o enfrentamento da violência contra o idoso. Contudo, apenas a produção de instrumentos legais não é suficiente para mudar a situação de violência a que está submetida a população idosa no país.

Além das medidas legais faz-se necessária uma mudança de visão da sociedade em relação ao ser idoso, como por exemplo, a mudança que passa pela educação no sentido mais amplo, e especificamente na formação dos profissionais, associadas à influência e ao poder que deve ter o Estado para fazer valer as leis por ele criadas.

\section{QUESTÕES ÉTI CAS DO ENFRENTAMENTO À VI OLÊNCI A CONTRA OS I DOSOS}


Florêncio MVL, Ferreira Filha MO, Sá LD. A violência contra o idoso: dimensão ética e política de uma problemática em ascensão. Revista Eletrônica de Enfermagem [serial on line] 2007 Set-Dez; 9(3):847-857. Available from: URL: http://www.fen.ufg. br/revista/v9/n3/v9n3a23.htm

$\mathrm{Na}$ definição de Marilena Chauí (19) a palavra violência significa usar a força para ir contra a natureza de algum ser, ir contra sua vontade; violência é violação; é transgressão contra as coisas que alguém acha justas e direitas, caracteriza relações intersubjetivas e sociais definidas pela opressão, intimidação, pelo medo e pelo terror. Ela se opõe à ética pois trata seres racionais como se fossem coisas, desprovidos de razão, vontade, liberdade e responsabilidade.

A violência nega valores universais dos seres humanos, como a igualdade, a justiça e a liberdade; consegue reduzir o valor da vida humana, e se constitui em violação absoluta dos direitos humanos ${ }^{(15)}$.

A violência contra o idoso é real, existe de fato, acontece na casa ao lado, das formas mais elementares: é a vizinha que se apodera da pensão da mãe; é o pai que é alojado no último cômodo da casa; é o neto que destrata o avô com ameaças; é a falta de cuidado com a administração da medicação. É o banho que não foi dado. A fralda que não foi trocada. É a divisão de bens antes da morte, com mecanismos de persuasão e coação física e psicológica do idoso. É o caçoar de sua demência e favorecer-se dela. É a agressão física simplesmente, sempre feita por alguém mais jovem e mais forte. É o abuso sexual das velhas acamadas, por seus conjugues. É o ostracismo do asilo.

É urgente a necessidade de tornar visível a violência contra o idoso para que ela seja reconhecida nos atos cotidianos e reprovada como atitude a-ética, porque praticada por sujeitos sociais livres que podem decidir por não praticá-la.
O reconhecimento de um ato ou comportamento de violência, e o seu repúdio, estão diretamente relacionados às capacidades de percepção e sensibilidade de cada indivíduo, que por sua vez dependem de valores éticos. Só a ética faz perceber e repudiar um ato de violência. Portanto a ética precisa ser cultivada em todas as instâncias da sociedade, como instrumento de preservação da própria vida humana.

A ética é o conhecimento à serviço da vida. Usar a ética nos casos de violência conduz o profissional (e demais pessoas) à reflexão e a busca de respostas a uma situação que se mostra ambígua e extrema ${ }^{(15)}$.

Os profissionais de saúde, no exercício de suas atribuições, devem tomar suas condutas baseados em atos morais, guiados por valores éticos, que devem ser reforçados durante sua formação profissional. É preciso despertar e manter a sensibilidade dos profissionais para com os atos de covardia e injustiça praticados contra a vida humana, até mesmo para que se evitem idiossincrasias, como a prática de negligência, abuso, e desrespeito pelos próprios profissionais de saúde, fato infelizmente comum no cotidiano.

Três componentes éticos são essenciais para o enfrentamento da violência pelos profissionais de saúde ${ }^{(15)}$ : o reconhecimento da dignidade das pessoas, o respeito pelo outro, e os valores humanos. Resumiríamos estes três componentes em uma só palavra: empatia. Saber pôr-se na situação do outro, sentir como ele sente, identificar-se com ele. Seria o suficiente para que vários atos de covardia e abuso fossem reconhecidos e combatidos não apenas entre profissionais de saúde, mas em toda a sociedade, amenizando 
Florêncio MVL, Ferreira Filha MO, Sá LD. A violência contra o idoso: dimensão ética e política de uma problemática em ascensão. Revista Eletrônica de Enfermagem [serial on line] 2007 Set-Dez; 9(3):847-857. Available from: URL: http://www.fen.ufg. br/revista/v9/n3/v9n3a23.htm

o sofrimento humano do ponto de vista físico e moral.

\section{CONSI DERAÇÕES FI NAIS}

A partir do acima descrito aponta-se a responsabilidade simultânea do Estado, da família e da sociedade para com o idoso. O enfrentamento do problema da violência contra o idoso não se finaliza na culpabilidade à família e na sua punição. De nada adianta culpar e punir a família se a ela não forem dadas oportunidades de modificação real do comportamento, o que requererá, muitas vezes, mudanças na conjuntura em que vivem.

Os programas de amparo e prevenção à violência contra o idoso precisam (8) “[...] estabelecer mecanismos de amparo à família, que é ao mesmo tempo quem promove os primeiros cuidados, e quem tem condições efetivas de prestar assistência permanente e continuada, e quem é autora de parcela importante das violências sofridas pelos idosos". É preciso considerar que as famílias têm limites de recursos financeiros, de disponibilidade, e inclusive limites emocionais, para suportar o fardo de tocar a própria vida e a vida de outro, ao mesmo tempo.

É neste ponto que o Estado precisa apresentar políticas de apoio, estendendo os limites da assistência através da implementação das ações que estão prevista no Estatuto do Idoso, no PAEVPI, e em outros documentos. Trata-se da criação e extensão de programas de assistência, como as 'casaslares' para idosos, centros de cuidados diurnos, centros de convivência, programas de internamento domiciliar bancados pelo SUS, melhor acessibilidade e atendimento pelo SUS, reinserção do idoso no mercado de trabalho, entre outras providências, que facilitariam a vida do idoso e de seus familiares, diminuindo os conflitos, e consequentemente, o risco da violência.

Como se percebe, atualmente no Brasil, existe amparo legal ao combate à violência contra o idoso, o que não existe é efetivação suficiente das medidas de prevenção por parte do Estado, nem respeito e abertura de visão por parte da sociedade, e nem conscientização e mais amor por parte das famílias.

Em relação ao profissional enfermeiro, este tem um papel significativo a desempenhar. Na sua lida direta e diária com os idosos usuários de serviços de saúde (de todos os níveis de complexidade), o enfermeiro precisa saber investigar e identificar os casos de violência, abordar corretamente o cliente, agir coordenadamente com outros profissionais, traçar intervenções eficazes para cada caso. Preventivamente, ele pode utilizarse de estratégias educativas de combate à violência contra o idoso nas comunidades.

O combate aos atos de violência às categorias mais frágeis da espécie humana deve começar na própria formação profissional do enfermeiro, que desde cedo deve ter seus valores éticos reforçados e ampliados por sua instituição formadora (15) .

Coibir a violência é um ato de cidadania. “Do ponto de vista social, o contrário da violência não é a não-violência, é a cidadania e a valorização da vida humana em geral e de cada indivíduo no contexto de seu grupo" (20).

\section{REFERÊNCI AS}

1. Netto MP, Yuaso DR, Kitadai FT. Longevidade: desafio no terceiro milênio. Rev. O Mundo da Saúde 2005 Out-dez; 29:594-606. 
Florêncio MVL, Ferreira Filha MO, Sá LD. A violência contra o idoso: dimensão ética e política de uma problemática em ascensão. Revista Eletrônica de Enfermagem [serial on line] 2007 Set-Dez; 9(3):847-857. Available from: URL: http://www.fen.ufg. br/revista/v9/n3/v9n3a23.htm

2. Minayo MCS. Violência contra idosos: o avesso do respeito à experiência e à sabedoria. Secretaria Especial dos Direitos Humanos, 2004.

3. Carvalho JAM, Garcia RA. O envelhecimento da população brasileira: um enfoque demográfico. Cadernos de Saúde Pública 2003 jun; 19: 725-733.

4. Minayo MCS. Violência contra idosos: relevância para um velho problema. Cadernos de Saúde Pública 2003 jun; 19: 783-791.

5. Organização Mundial de Saúde (OMS). Relatório Mundial sobre Violência e Saúde. Organização Mundial de Saúde 2002; 1:1-42.

6. Mendonça J. Plano de ação para o enfrentamento da violência contra a pessoa idosa. Reunión de Gobiernos y Expertos sobre Envejecimento de Países de América del Sur. 2005.

7. Minayo MCS, Souza ER. Violência contra idosos - é possível prevenir. Ministério da Saúde. Secretaria de Vigilância em Saúde, 2005.

8. Fonseca MM, Gonçalves HS. Violência contra o idoso: suportes legais para intervenção. Rev. Interação em Psicologia 2003 jul-dez; 2:121128.

9. Gaioli CCLO. Ocorrências de maus-tratos em idosos no domicílio [dissertação]. Ribeirão Preto; 2004.

10. Gawryszewski VP, Jorge MHPM, Koizumi MS. Mortes e internações por causas externas entre idosos no Brasil: o desafio de integrar a saúde coletiva e atenção individual. Rev. Assoc. Med. Bras. 2004; 50: 97-103.

11. Pena FB; Santo FHE. O movimento das emoções na vida dos idosos: um estudo com um grupo da terceira idade. Revista Eletrônica de Enfermagem [serial online] 2006 jan-abr [cited 2006 jun 15]; 8 (1):17-24. Avalaible from:

URL:

http://www.fen.ufg.br/revista/revista8_1/origi nal 02.htm.

12. Santos ACPO, Silva CA, Carvalho LS, Menezes MR. A construção da violência contra idosos. Rev. Bras. Geriatria e Gerontologia 2007; 10(1).

13. Institute of Gerontology Candido Mendes University. Report on elder abuse in Brazil. Rio de Janeiro: 2001.

14. Cattani RB, Girardon-Perlini NMO. Cuidar do idoso doente no domicílio na voz de cuidadores familiares. Revista Eletrônica de Enfermagem [serial online] [cited 2006 junho 20]; 6 (2):254-271. Available from: URL: http://www.fen.ufg.br/revista/revista6_2/idoso .html
15. Figueroa, AA. Aspecto éticos vulnerados em situaciones de violência: su importância em la formación de enfermería. Invest. educ. enferm.[serial online] [cited 2007 julho 10] ; 23 (2):104-116. Available from: URL: http://www.scielo.org.co/scielo.php?script=sci arttext\&pid=S0120-

$\overline{53072005000200009 \& l n g=e s \& n r m=i s o \& t \mid n g=e}$ $\underline{\mathrm{s}}$

16. Portaria no. 1.395/GM, 10 de dezembro de 1999.

17. Lei no $10.741,1$ ㅇ de outubro de 2003.

18. Ministério da Saúde. Brasil. Secretaria de

Políticas de Saúde - Política Nacional de Redução da Morbimortalidade por Acidentes e Violência. Revista Saúde Pública.[serial online] [cited 2000 jan 15]; 34 (4):427-430. Available from: URL:

http://www.scielo.br/pdf/rsp/v34n4/2545.pdf

19. Chaui, M. Cultura e Democracia: o discurso competente e outras falas. 11 ed (Cortez). São Paulo: Cortez, 2006.

20. Minayo MCS. Violência como indicador de qualidade de Vida. Revista Acta Paul Enf, 2000; 13 (parte1) : 159-165.

Artigo recebido em 05.12.06

Aprovado para publicação em 10.12.07 